\title{
The effective oxidation pressure of indium-oxygen system
}

\author{
E. Ricci $\cdot$ T. Lanata $\cdot$ D. Giuranno . \\ E. Arato
}

Received: 26 November 2007 / Accepted: 17 December 2007/Published online: 8 March 2008

(C) Springer Science+Business Media, LLC 2008

\begin{abstract}
A theoretical model on oxygen transport at the surface of liquid metals has been validated by dynamic surface tension measurements performed on liquid Indium as test metal. The oxygen contamination conditions have been obtained at different oxygen partial pressures under both low total pressure (Knudsen regime) and inert atmospheric pressure (Fick regime) conditions, confirming that an oxide removal regime occurs under an oxygen partial pressure much higher than the equilibrium one (the "Effective Oxidation Pressure"). Experimental results are reported which give a further insight on the relative importance of the various processes due to the oxygen mass transport between the liquid metal and the gas phase. The critical aspects involved in surface tension measurements of liquid metals, related to the problem of liquid metal-oxygen interactions, are also underlined.
\end{abstract}

\section{Introduction}

The interactions between liquid metals and their environments (vapour phase and working atmosphere) can be understood by analysing the surface properties of the metals. The capillary properties, in particular the surface tension, are strongly affected by surface cleanliness, which depends on the surrounding atmosphere and, for liquid

E. Ricci - T. Lanata - D. Giuranno - E. Arato

CNR-IENI Genoa, Via De Marini, 6, 16149 Genoa, Italy

T. Lanata $\cdot$ E. Arato $(\bowtie)$

DICAT-University of Genoa, Via Opera Pia 15, 16145 Genoa, Italy

e-mail: Elisabetta.Arato@dicat.unige.it metals in particular, on its oxygen content. Oxygen can either dissolve into the liquid phase or form an oxide film on the surface of the liquid metal $[1,2]$. In most cases the Gibbs Adsorption Equation [3] or the derived adsorption isotherms [4-7], which account for the decrease in the interfacial free energies when the oxygen activity increases, are applied to explain the mechanism of oxygen adsorption at the liquid metal-gas interface. The differences in the interpretations arise principally from the difficulties of performing surface properties' determinations using controlled values of oxygen present in the gas phase. In addition, when dealing with high-temperature measurements of metallic systems, vaporisation phenomena generally occur and have to be taken into account.

Several experiments [8] have clearly shown that a flux of metallic vapours occurs in the direction opposite to the oxygen flow. The effect of oxygen partial pressure on the vapourisation rate of metals, which depends linearly on the oxygen content of the surrounding gaseous atmosphere, has been verified [9]. Moreover, for those molten metals that form volatile oxides there will also be a flow of metal oxides leaving the liquid surface. In this case, the oxygen transfer from the gas phase to the condensed phase must account for the double contribution of molecular oxygen and the oxygen linked as oxide. Many theoretical and experimental studies of these effects are available in literature for solid metals [10]. In fact, purification processes by means of oxide and sub-oxide evaporation at high temperature are extensively used in metal refining. The dependence of the rate of the oxidation on the gas composition at a high temperature was discussed theoretically in [11].

To have a complete approach to the study of oxygen interactions with the liquid metal and of its influence on the material properties, in particular the surface properties, it is clear that a correlation needs to be established between the 
kinetics of vapour fluxes and thermodynamic equilibrium. The estimation of both the degree of contamination and the mechanism of the gas mass-transfer at the liquid metal-gas interface have been provided by different theoretical models [12-14]. The application of these models is even more useful when dealing with the measurements of the surface properties of metals of particular technological interest, such as silicon $[15,16]$, tin $[17,18]$ or aluminium $[19,20]$.

The aim of this paper is to obtain a further confirmation of the main result previously demonstrated $[18,19]$ : i.e. the true operative parameters of the surface oxidation/de-oxidation conditions can be described through the definition of the Effective Oxygen Pressure [1]. In fact, the description presented here concerns the dynamic surface tension measurements of liquid indium, performed to determine the interactions of oxygen with that metal through the validation of the theoretical oxidation/de-oxidation curve under both low total pressure and atmospheric pressure.

\section{Experimental}

The high melting temperature and chemical reactivity of most metals increase the experimental difficulties in performing thermophysical properties' measurements. The lack of accuracy can be caused by the numerous sources of errors, for example, impurities coming from the base material, from the container material or the environment. However, some uncertainties on measurements could still exist, essentially due to the shortage of the experimental evaluation of the oxygen content.

Among the thermophysical properties, the surface tension is certainly the parameter most sensitive to the interaction of the oxygen and the metal. This is one of the reasons why surface tension measurements of pure metals are so much affected by a great uncertainty [20]. In turn, performing systematic dynamic surface tension measurements, the liquid metal surface evolution can be successfully observed as a function of the surrounding atmosphere.

The large-drop technique is a suitable method for performing systematic dynamic surface tension measurements on liquid metals and alloys [21, 22]. In this case, the solid support is a special circular crucible with sharp edges. The design of the edges of the crucible blocks the triple line at an "apparent" contact angle that is much higher than the real one and the axis-symmetry of the drop can be imposed. A further advantage of this method is the high accuracy due to the large drop used, in fact the size of the drop was chosen so that the error in surface tension did not exceed $1 \%$.

In addition, due to the difficulties in performing reliable measurements at high temperature, some standard criteria have to be follow in the building of the apparatus and in the procedures, as described in [23]. The experimental apparatus used for the dynamic surface tension determinations has already been described in [18]. Recently it has been supplemented with three solid-state electrodes (POASSetnag $\left({ }^{\circledR}\right)$ with internal metal/oxide reference, each kept at its optimal working temperature, allowing the oxygen partial pressure to be monitored at different sites in the apparatus: (a) inside the chamber; (b) at the inlet of the feed gas; (c) at the outlet of the exhaust gas. In addition, a high-precision flow meter and a micro-leak valve have allowed a precise and controlled amount of the gas flux inside the chamber and an ion gun and gas supply system have allowed the cleaning of the molten sample surface by argon ion sputtering.

Samples of the highest purity (99.9999 Marz grade) Indium of about $2.5 \mathrm{~g}$ were mechanically abraded and chemically cleaned with an organic solvent in an ultrasonic bath. The sample was placed in a non-oriented monocrystalline alumina (sapphire) crucible $(r=5.5 \mathrm{~mm})$. The crucible with the sample was laid on an alumina holder sliding in the experimental apparatus. When the apparatus conditions (temperature, oxygen partial pressure) were reached, the sample was introduced into the centre of the furnace by a pushrod magnetic manipulator. The drop profile of the sample in the crucible was acquired by a CCD camera and processed with adhoc acquisition software [24] in a LABView ${ }^{\circledR}$ environment. This acquisition procedure allows real-time surface tension measurements to be made and, at the same time, the values of the surface tension and the other parameters (sample temperature and oxygen partial pressure) to be followed. Due to its high performance in terms of time of acquisition and reliability (up to 10 points per second with an accuracy up to $0.1 \%$ ), it is particularly suitable for both static and dynamic measurements. The magnification factor of the system was calculated for each shape acquisition with an internal reference. The density, as a function of temperature, was introduced from literature data [25]. When compared to other sources [26, 27], the differences in the density data of the Indium were less than $0.5 \%$ over the temperature range investigated.

To obtain the actual experimental curve, indicating the oxygen tensioactive effect on the liquid metal an experimental isobaric procedure was utilised, where the imposed temperature was changed under the constant oxygen partial pressure of the feed gas until the effect of oxygen is found [18]. The tensioactivity is revealed by the change of the temperature coefficient sign. The advantage of the isobaric procedure over the isothermal one was that the variations in temperature can be set automatically.

As saturation conditions strongly depend on temperature, a temperature modulation corresponds to a modulation of the 
saturation level and it is then equivalent to a modulation of oxygen concentration in the liquid phase [23]. The results of the application of the isobaric procedure to molten indium are reported and discussed below.

\section{Results and discussion}

The experimental tests were performed varying the temperature at a rate $=5 \mathrm{~K} / \mathrm{min}$, under both Knudsen regime and inert gas flux, in the temperature ranges $533-833 \mathrm{~K}$ and 773-1,073 K, respectively. Surface tension measurements were made at 1 min intervals. In Fig. 1, an example of a test performed under the Knudsen regime $\left(P_{\text {tot }} \approx 10^{-3} \mathrm{~Pa}\right)$ is shown, the oxygen partial pressure being constant and equal to $2.6 \times 10^{-4} \mathrm{~Pa}$. The temperature was increased and decreased between 533 and $833 \mathrm{~K}$. The temperature modulation allows some significant inversions in the surface tension behaviour to be noted. The meaning of the 'inversions' are clearly explained in [23]. Following the behaviour shown in Fig. 1, if a negative temperature coefficient is assumed characteristic of pure In, the oxygen tension-active effect over the liquid becomes evident between point ' 1 ' and ' 2 '. When temperature increases, the slope of the surface tension versus temperature is positive showing the presence of an oxygen adsorption [23]. The position of ' 2 ' can be approximately symmetrical to that of ' 1 ' as a sign of the reversibility oxygen dissolution in the metal drop. The portion of the curve between ' 1 ' and ' 2 ' reflects the surface adsorption due to the segregation of the oxygen dissolved into the liquid bulk (consequence of the variation of temperature) more than the effect of the external imposed oxygen partial pressure. The experimental conditions of the inversion (' 1 ' or ' 2 ' coordinates) are linked to tension-active effect, but not necessarily to the formation of stable oxides on the surface [28] and this effect is identified by the sign inversion (actually from negative to positive) of the temperature coefficient of the surface tension. Positive temperature coefficients are not usually reported in literature, probably because they are considered the consequence of heavy contamination. On the other hand, in our experiments, the temperature coefficients for what we consider a 'clean' surface are easily repeatable, and the sign inversions, when they occur, are easily detectable. Considering several consecutive decreasing and increasing temperature segments, the behaviour of surface tension with the temperature is almost univocal: its symmetry derives from the temperature dependence of the oxygen solubility product which is responsible for the bulk oxygen segregation towards the surface.

This is particularly evident looking at Fig. 2, where the data of the same test of Fig. 1 (only for the segments characterised by a temperature variation) are shown in the $(\gamma, \mathrm{T})$ plane.

In the light of these facts, the identification of the sign inversion with the saturation of the interface, which is the incoming formation of an oxide phase, appears to be a reasonable assumption [23]. The same behaviour had already been observed for a tin/oxygen system [18] and aluminium/ oxygen system [19]. However, in the case of tin, a slight difference between the theoretical Effective Oxygen Pressure curve and experimentally available $\left(P_{\mathrm{O}_{2}}, T\right)$ values exists: the latter are higher than the thermodynamic value and the theoretical curve, due to the contribution of the linked oxygen in the form of sub-oxides and the oxygen diffusion inside the bulk phase [29]. In the In-O system under Knudsen
Fig. 1 Dynamic surface tension of Indium under Knudsen regime $\left(P_{\text {tot }} \approx 10^{-3} \mathrm{~Pa}\right)$ at constant oxygen partial pressure $\left(P_{\mathrm{O}_{2}}=2.6 \times 10^{-4} \mathrm{~Pa}\right)$. The temperature was increased and decreased between 533 and $833 \mathrm{~K}$. Two inversion points are highlighted $(1,2)$

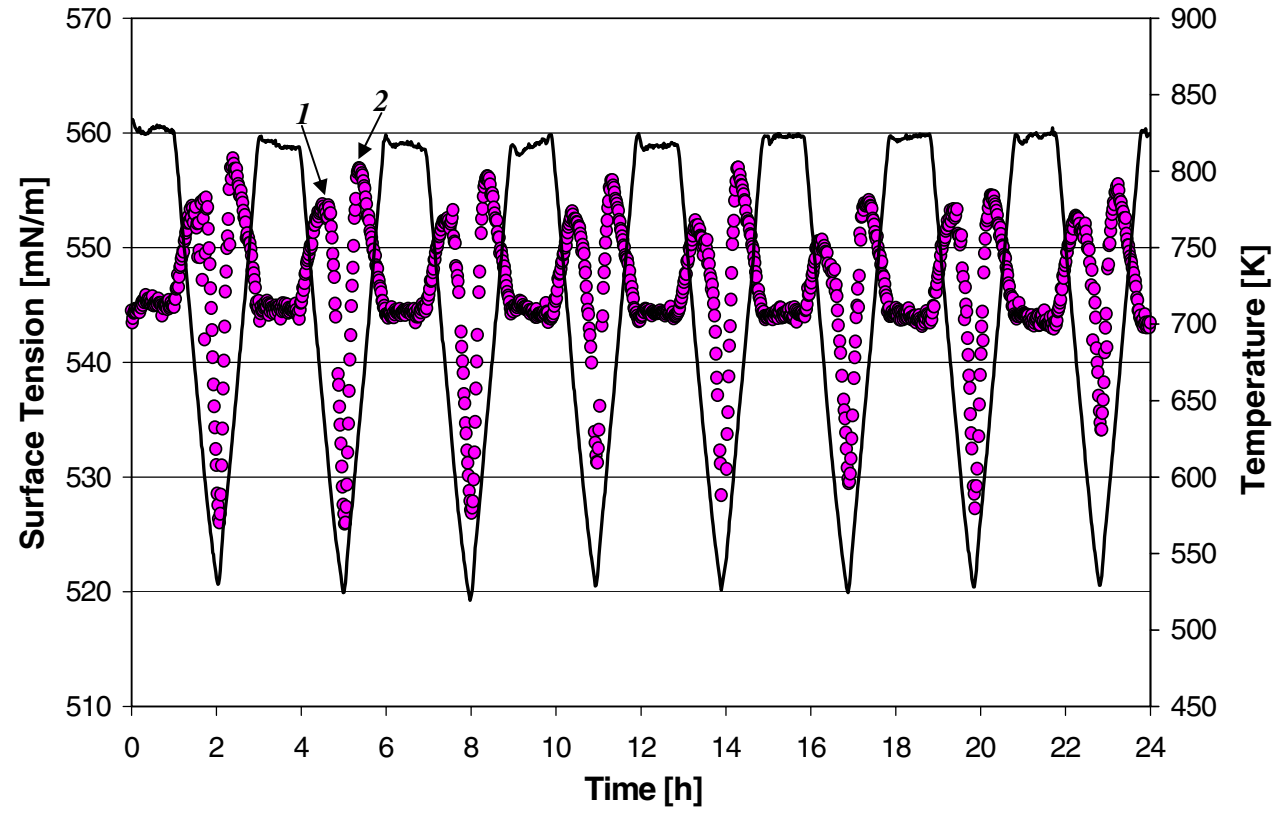


Fig. 2 Surface tension values of Fig. 1 as a function of decreasing and increasing temperature

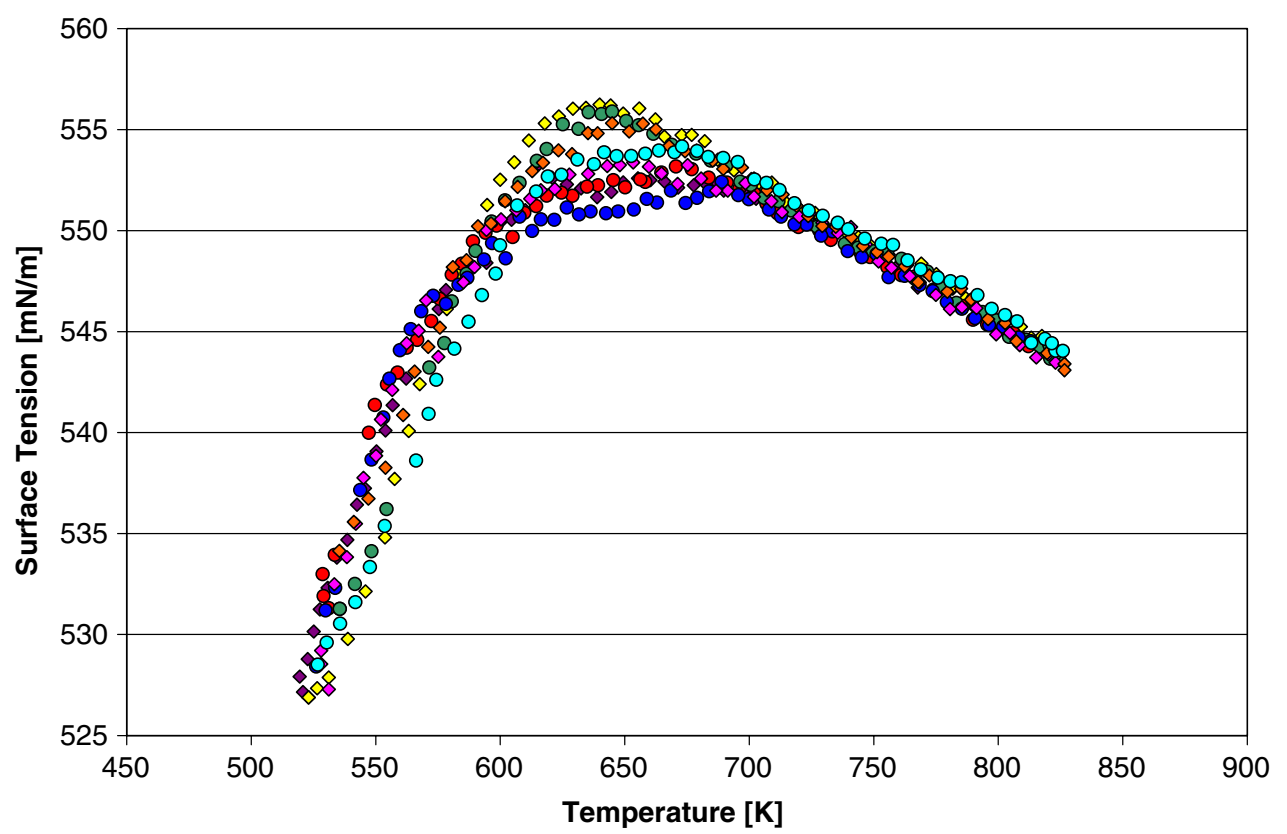

regime, the oxygen fluxes to and from the oxidised surface originated in the vaporisation of a compact oxide layer $\left(\mathrm{In}_{2} \mathrm{O}_{3}\right)$ during its decomposition into other oxides and a three-phase mono-variant equilibrium was assumed [29]. These conditions are the same as those given by the model presented by Castello et al. [1] but with the calculated results shifted towards higher residual pressure values because the sub-oxide vapour pressures (in particular $\mathrm{In}_{2} \mathrm{O}$ ) were maximised under the three-phase equilibrium conditions [30].

Under atmospheric pressure, the molecular diffusion is assumed to be the main process controlling the exchange of matter between the liquid metal and the surrounding atmosphere. In this case, chemical reactions in the gaseous layer are also taken into account and it is possible to verify that the liquid metal is under steady-state conditions, which are different from those of thermodynamic equilibrium. When an inert gas flux (Ar-N60; $\left.P_{\text {tot }}=10^{5} \mathrm{~Pa}\right)$ was experimentally applied, different behaviours were found, depending on both the initial status of the metal drop and the gas flow rate. In Fig. 3 the results of a test performed under a low gas flow rate $\left(0.05 \mathrm{~L} / \mathrm{min} ; P_{\mathrm{O}_{2}}=5 \times 10^{-3} \mathrm{~Pa}\right.$ in the inlet inert gas), in the temperature range 773$1,073 \mathrm{~K}$ are shown. The oxygen partial pressure $P_{\mathrm{O}_{2}}=4 \times$ $10^{-13} \mathrm{~Pa}$ was measured inside the test chamber. Under these conditions the inversion points were not observed during the experiment (time $\exp >16 \mathrm{~h}$ ) and the surface tension behaviour indicated that the liquid metal drop was always in the de-oxidation regime as foreseen by the Effective Oxygen Pressure curve calculated for the In-O system. In Fig. 4 an example of a test carried out at constant $P_{\mathrm{O}_{2}}=5 \times 10^{-3} \mathrm{~Pa}$ in the inlet inert gas, while varying the temperature is reported. The variation in the temperature over time was set at $5 \mathrm{~K} / \mathrm{min}$, the temperature was in the range $773-1,073 \mathrm{~K}$ and the oxygen flux was maintained at a constant value of $0.05 \mathrm{~L} / \mathrm{min}$. In the first $8 \mathrm{~h}$, it was possible to observe a sequence of inversion points that progressively disappear and an increase of the value of the surface tension corresponding to the lowest temperature. In the meantime, a progressive decrease in the oxygen partial pressure (from $P_{\mathrm{O}_{2}}=10^{-4}$ to $P_{\mathrm{O}_{2}}=10^{-13} \mathrm{~Pa}$ ) inside the test chamber over time was monitored by the sensors.

The fundamental point is that the entire test was carried out in surface de-oxidation conditions, for which reason the trend reported in the figure is not correlated to the value of $P_{\mathrm{O}_{2}}$ inside the test chamber, but is linked to the initial concentration of the dissolved oxygen in the metal sample. The inversion point marks a concentration threshold of dissolved oxygen in the drop above which oxygen manifests its tensioactive character in relation to Indium. This threshold concentration should correspond to the saturation level of oxygen in the metal, and the point at which it begins to form an oxide on the metal surface. When the temperature is reduced the solubility of oxygen is also reduced [31] and it then reaches its saturation concentration on the surface and in the bulk. In fact, when lowering the temperature, if the drop is "clean", the surface tension increases at first, according to the behaviour of pure liquid, then as saturation is approached, the oxygen content in the liquid surface increases and the surface tension begins to decrease. The maximum surface tension for a decrease in temperature or the minimum surface tension when temperature increases corresponds to incoming oxidation points.

As the system is in surface de-oxidation conditions, the oxygen level inside the sample falls over time and, in the 
Fig. 3 Dynamic surface tension of Indium under Ar flow rate $=0.05 \mathrm{~L} / \mathrm{min}$ $\left(P_{\mathrm{O}_{2}}=5 \times 10^{-3} \mathrm{~Pa}\right.$ in the inlet inert gas); Temperature range $=773-1,073 \mathrm{~K}$; $P_{\mathrm{O}_{2}}=4 \times 10^{-13} \mathrm{~Pa}$

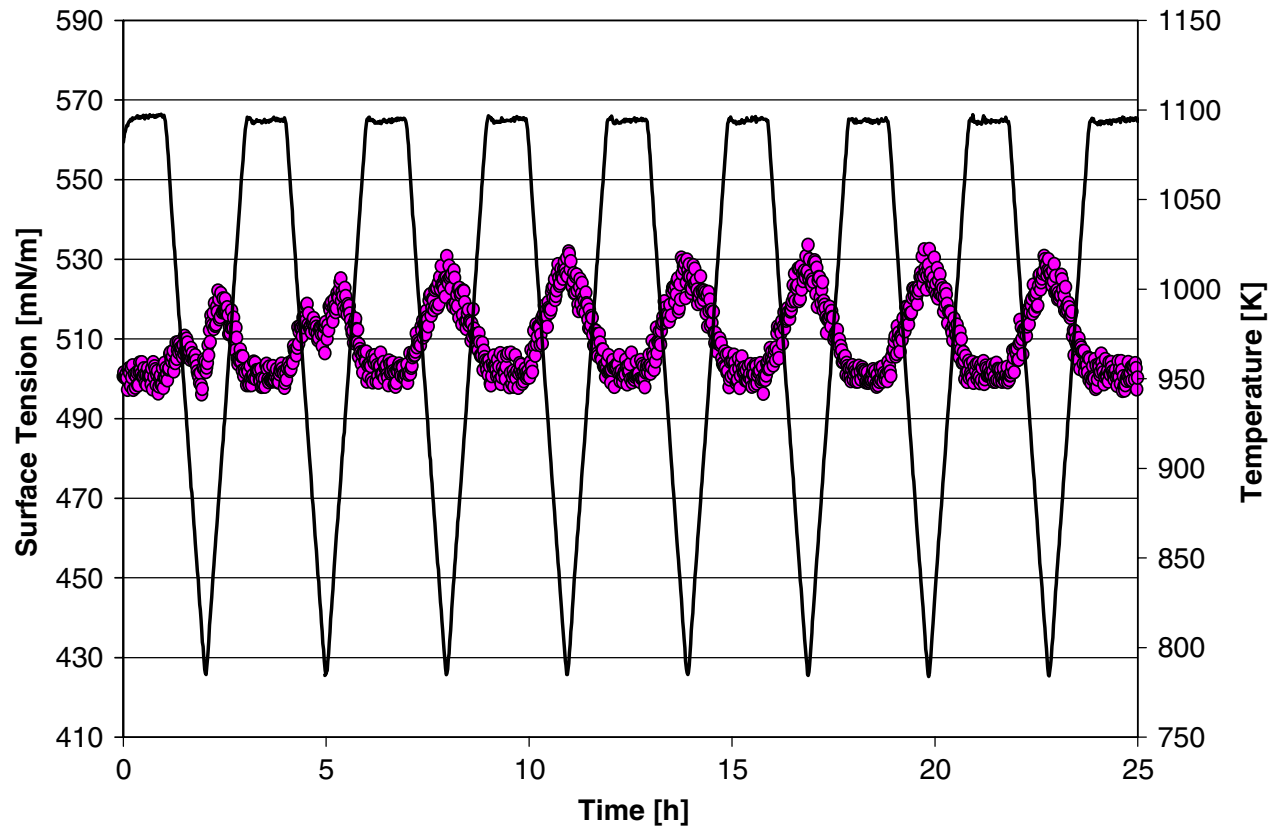

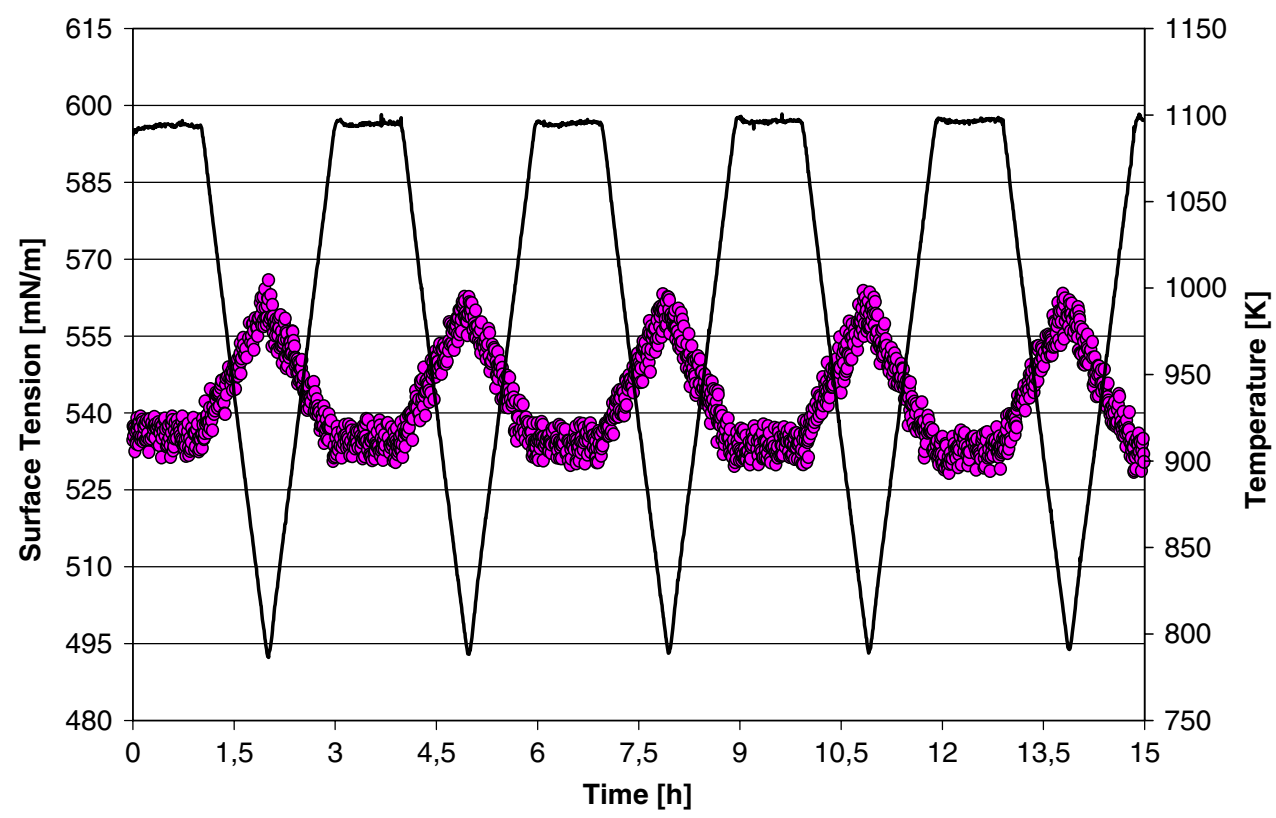

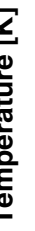

Fig. 4 Dynamic surface tension of Indium under Ar flow rate $=0.05 \mathrm{~L} / \mathrm{min}$ $\left(P_{\mathrm{O}_{2}}=5 \times 10^{-3} \mathrm{~Pa}\right.$ in the inlet inert gas); Temperature range $=773-1,073 \mathrm{~K}$; Oxygen partial pressure, from $P_{\mathrm{O}_{2}}=10^{-4}$ to $P_{\mathrm{O}_{2}}=10^{-13} \mathrm{~Pa}$ 
Fig. 5 Surface tension of Indium (see test of Fig. 4) as a function of temperature at different oxygen partial pressure

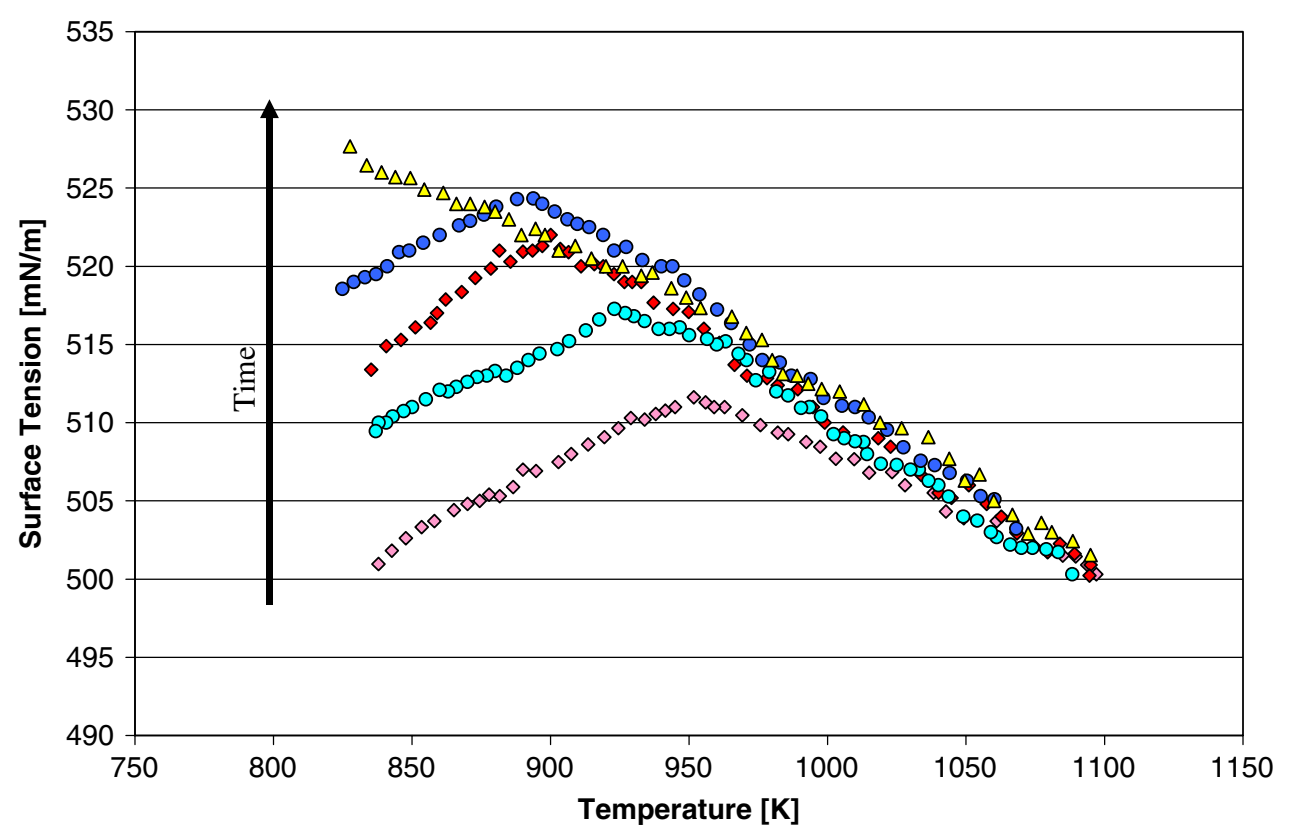

$2 \mathrm{mN} / \mathrm{m}$ in the "linear section" $(T>973 \mathrm{~K})$; (b) the temperature coefficient of the surface tension of indium is independent in a finite range of dissolved oxygen concentration of values of the same concentration.

A similar behaviour was already observed for the tinoxygen system and described in detail in [28].

Finally, in Fig. 6, the Effective Oxygen Pressure curve calculated for the In-O system is shown (bold line). This quantity is the true limit value of the oxygen partial pressure, discriminating between the surface oxidation and deoxidation regimes for the In-O system and is, as expected, several orders of magnitude (up to $30 \mathrm{o.m}$.) higher than the corresponding value of the thermodynamic equilibrium gas/condensed phase [32] ( $P_{\mathrm{O}_{2}}^{\mathrm{s}}$-broken line). Liquid masstransfer phenomena are also considered [33] so that only the liquid metal-gas interface could be assumed stationary, and the oxidation pressure becomes proportional to the solubility of oxygen in the metal [23]. When all the experimental points (e.g. under Knudsen regime and under inert gas flux), which characterised the inversion of the surface tension versus temperature measured during the dynamic surface tension tests are reported in the Effective Oxygen Pressure diagram, a very good agreement is observed (Fig. 6).
Fig. 6 Effective Oxygen Pressure curve calculated for the In-O system (bold line) compared with the oxygen partial pressure values of the thermodynamic equilibrium gas/condensed phase [32] (broken line). Experimental points: under Knudsen regime; $\boldsymbol{\Delta}$ under Fick regime

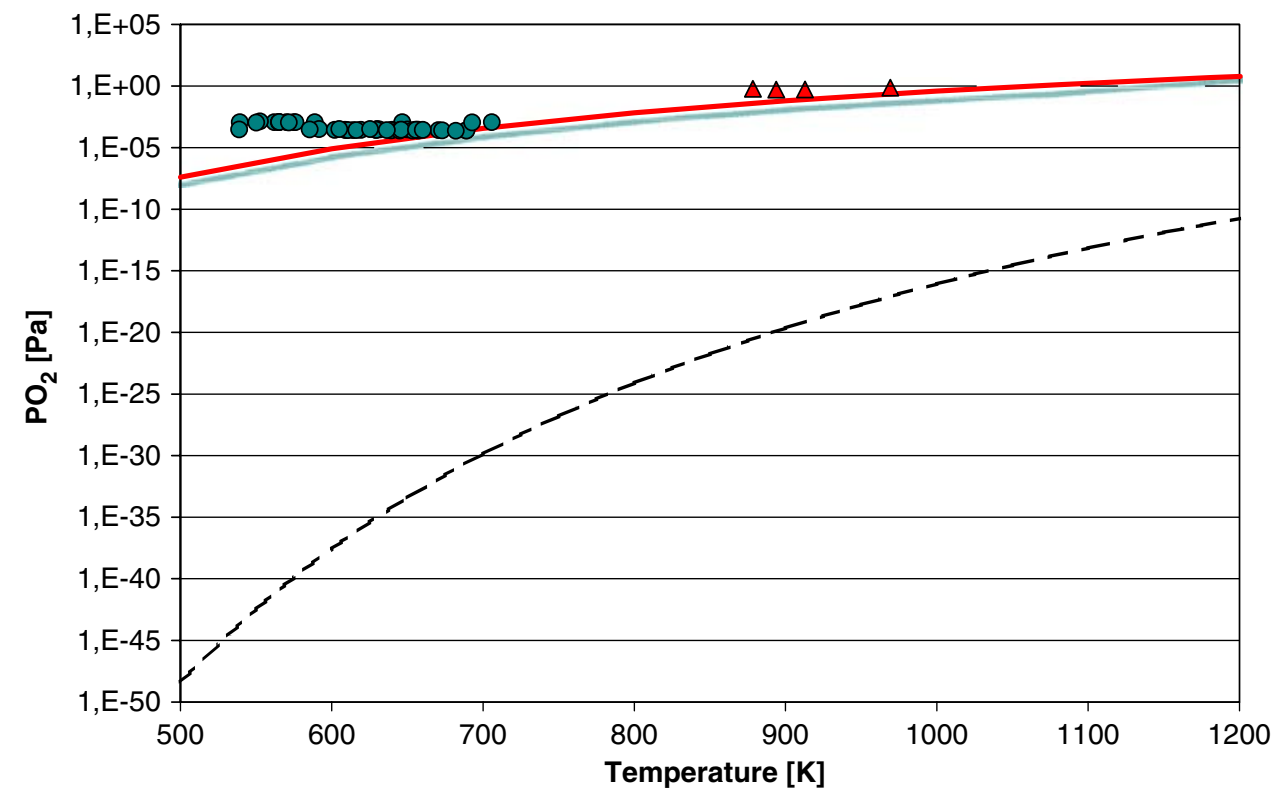




\section{Conclusions}

The phenomena of oxygen transport at the molten metalatmosphere interface and particularly the mechanisms whereby a molten metal or alloy surface is kept clean even in the presence of $\mathrm{O}_{2}$ impurities in the gas, play a very important role in most high-tech processes.

From the results obtained from our models, it is possible to straightforwardly explain the mechanisms which keep a molten metallic system oxygen-free, despite the thermodynamic driving force, due to an oxygen flux in the opposite direction to the oxide bond.

The experimental results based on the In-O system using dynamic surface tension measurements show once again that the experimental oxidation/de-oxidation transitions occur at values very close to those predicted by the models and, therefore, higher than the thermodynamic values, owing to the non-negligible contribution of the linked oxygen in the form of the volatile $\operatorname{In}_{2} \mathrm{O}$ sub-oxide.

The stationary drop assumption leads to the definition of an Effective Oxygen Pressure curve that well describes the indium experimental data: the data show a very good agreement with the theory when liquid mass-transfer effects are taken into account.

Acknowledgement The authors wish to thank Paolo Costa for his contributions to this work.

\section{References}

1. Castello P, Ricci E, Passerone A, Costa P (1994) J Mater Sci 29:6104. doi:10.1007/BF00354549

2. Eustathopoulos N, Nicholas MG, Drevet B (1999) In: Cahn RW (ed) Pergamon material series. Elsevier, Amsterdam

3. Defay D, Prigogine I (1966) Surface tension and adsorption. Longmans, London

4. Ricci E, Passerone A, Joud JC (1988) Surf Sci 206:533

5. Chatain D, Chabert F, Ghetta V, Fouletier J (1993) J Am Ceram Soc 76:1568

6. Backhaus-Ricoult M (2000) Acta Mater 48:4365
7. Lee JH, Tanaka T, Yamamoto M, Hara S (2004) Mater Trans 453B: 625

8. Nogi K, Ogino K, McLean A, Miller WA (1986) Met Trans B $17: 163$

9. Turkdogan ET, Grieveson P, Darken LS (1963) J Phys Chem 67:1647

10. Gelain C, Cassuto A, Le Goff P (1971) Oxid Met 3:139

11. Wagner C (1958) J Appl Phys 29:1295

12. Laurent V, Chatain D, Chatillon C, Eustathopoulos N (1988) Acta Met 36:1797

13. Ricci E, Passerone A, Castello P, Costa P (1994) J Mater Sci 29:1833. doi:10.1007/BF00351303

14. Ratto M, Ricci E, Arato E, Costa P (2000) J Cryst Growth 217:233

15. Azami T, Nakamura S, Hibiya T (2001) J Cryst Growth 223:116

16. Ratto M, Fiori L, Ricci E, Arato E (2003) J Cryst Growth 249:445

17. Ricci E, Castello P, Passerone A, Costa P (1994) Mater Sci Eng A 178:99

18. Fiori L, Ricci E, Arato E (2003) Acta Mater 51:2873

19. Giuranno D, Ricci E, Arato E, Costa P (2006) Acta Mater 54:2625

20. Molina JM, Voytovych R, Louis E, Eustathopoulos N (2007) Int J Adhes Adhes 27:394

21. Naidich V (1981) Progress in surface and membrane science. Academic Press, New York

22. Passerone A, Ricci E (1998) In: Mobius D, Miller R (eds) Drops and bubble in interfacial research. Elsevier, Amsterdam

23. Ricci E, Arato E, Passerone A, Costa P (2005) Adv Colloid Interface Sci 117(1-3):15

24. Liggieri L, Passerone A (1989) High Temp Technol 7:82

25. Lucas LD (1999) Tech Ing M:65

26. Iida T, Guthrie RIL (1993) The physical properties of liquid metals. Clarendon Press, Oxford

27. Lang G (1990) Handbook of chemical physics. CRC Press, New York

28. Fiori L, Ricci E, Arato E, Costa P (2005) J Mater Sci 40(910):2155. doi:10.1007/s10853-005-1907-x

29. Arato E, Ricci E, Costa P (2005) J Mater Sci 40(9-10):2133. doi: 10.1007/s10853-005-1904-0

30. Samsonov GV (1973) The oxide handbook. IFI-Plenum, New York

31. Otsuka S, Kozuka Z (1981) Trans Jpn Inst Met 22:558

32. Knacke O, Kubashewski O, Hesselmann K (1991) Thermochemical properties of inorganic substances, 2nd edn. Springer Verlag, Duesseldorf

33. Arato E, Ricci E, Fiori L, Costa P (2005) J Cryst Growth 282:5 